\title{
Reconstruction of Mathematics Pedagogy Curriculum System from the Perspective of Transition of Teachers Colleges
}

\author{
Youjun Li \\ Ningxia Normal University, Guyuan, Ningxia, 756000
}

Keywords: Higher Normal Education Transformation, Mathematics Education, Curriculum System

\begin{abstract}
The transformation of colleges and universities requires colleges and universities to apply to the development of multi-disciplinary, curriculum system, all-round transition, these requirements for mathematical mathematics education curriculum and mathematics education curriculum content system construction poses a serious challenge to our school actual and current mathematics Education content, teaching methods, evaluation of teaching problems, put forward the content structure of streamlining, optimizing and reorganizing mathematics education curriculum from three aspects of the content system, teaching methods and teaching evaluation of mathematics education, Pedagogic content module, integrate course teaching content, improve teaching mode, adopt scientific and reasonable measure of assessment and reform measures, with a view to improve the quality of teaching of this course and cultivate a new type of mathematics teacher.
\end{abstract}

\section{Introduction}

In accordance with this requirement, 600 new undergraduate colleges and universities nationwide are facing the problem of transformation. The transition policy will affect all aspects of the original teaching system of colleges and universities for transition to higher vocational colleges, Specific implementation to the concept of updating, professional construction and personnel training mode construction and other issues. The Ministry of Education, "Guiding Opinions on Guiding the Transformation of General Undergraduate Colleges and Universities to Applied Type in Some Local Areas," clearly states: the content of the curriculum and vocational standards, the docking between the teaching process and the production process; the change of the teaching concept from a teacher center to a student center; and the teaching content from knowledge Teaching mainly from the first to the second classroom, business classrooms, community classrooms, online classes and international classroom comprehensive extension of change; teaching methods from full irrigation irrigation to the organization to discuss and guide the enlightenment change, Comprehensively promote case teaching and project teaching; expand students 'learning autonomy and implement student-centered heuristic, cooperative and participatory teaching, and gradually expand students' right to choose their own majors and curricula; requirements for teaching materials are both theoretical and practical Training; internship links, the establishment of operations, internships, employment ... "one-stop" training mode, after the transformation of colleges and universities will be able to cultivate practical ability, strong sense of innovation, truly meet the job requirements of the industry and job skills of skilled personnel.

The mathematics and applied maths of higher normal majors are mainly for the training of future math teachers, while mathematics education courses are the landmark courses of maths majors, which to a certain extent determine the professional qualities of math teachers in the future. Mathematics pedagogy course is a subject for mathematics normal students to learn mathematics teaching theory, study mathematics teaching law and train mathematics teaching skill. However, there are some problems in current mathematics education in normal colleges, whether from the content system or from the teaching methods. For the problem, consider the requirements of the transformation and development, reconstruction of mathematics education curriculum system is a top priority. 


\section{The Current Situation and Problems of the Current Situation Setting of Mathematics Education Courses}

From the 1950s to the 1980s, the mathematics education curriculum in our country mainly includes "Mathematics Teaching Method for Middle School" and "Elementary Mathematics Study". Great changes have taken place since the 1980s, and mathematics education has gone through the process of teaching mathematics in middle schools - mathematics teaching - mathematics education. However, a comprehensive survey of the national mathematics education curriculum can be described as a wide range of different systems, what kind of system is still not a unified norms, in particular, mathematics education courses "to teach what, how to teach," the problem has not been solved, the content How to determine so far there is no consensus, the current normal colleges and universities have their own different views and practices. The content of teaching in "Mathematics Pedagogy" and "Mathematics Teaching Theory" teaching content is also very confusing, there are many unsatisfactory aspects in the teaching methods and assessment methods, especially "This is a teacher do not want to teach, students The so-called unlucky course of unwillingness to learn. "Ubiquitous issues can be summarized in the following areas:

In recent years, the curriculum is set up as follows: Compulsory courses include mathematics education (or mathematics teaching theory), mathematics education research methods, mathematics curriculum design and evaluation, mathematics teaching material analysis and research, mathematics education psychology, mathematics education skill training, Competition math, history of mathematics. Elective courses include mathematics learning strategies for math teachers vocational skills development, mathematics teachers professional standards training, mathematics teaching evaluation. Some of these courses do not have textbooks, teaching materials for practice courses are scarce, some have textbooks, but the textbooks lack new ideas, new contents, and new methods in current educational theories.

Practical teaching links include math teaching practice observation, mathematics micro-teaching ability training and math education teaching practice (two months). But did not set up the course of mathematics micro-grid teaching, micro-training only allows students to complete their own 18 hours before the internship, completely mellored in the form, not in accordance with mathematical micro-teaching "theory of micro-playback video comment feedback role replay "this procedure to carry out.

The structure of the course is imperfect and contradictory. Most courses are almost the same, and the existing courses are overlapped and overlapped, and the courses are out of practice, which are not in conformity with the laws of education and the needs of students' development. They can no longer meet the current basic education The need of reform; over-emphasizing the integrity and comprehensiveness of the knowledge system; the lack of necessary integration and simplification among branches; the excessive emphasis on systematicness; the unreasonable proportion of curricula; and the lack of opportunities for students to freely choose and combine.

In the teaching of mathematics education, we often adopt the mode of "imparting and accepting". The teaching methods and methods are basically the old form of apprenticeship with master. In practical teaching, they emphasize theory and practice, Light optimization; reunification, light personality; lack of demonstration of teaching methods, teaching activities focused on the classroom, students have no subtle demonstration effect, the students are limited to the learning of teaching materials, a single form. Lack of other auxiliary teaching methods, focusing on teaching skills training "micro-teaching" and carried out very little. College before the internship in teaching skills standards training for all teachers to participate in the guidance of the training of normal students skills, but still did not fundamentally change the status quo weak guidance of skills training.

Evaluation mode basically deducts "examination-oriented education" mode, especially the pen test type is mostly open-minded, teacher training of normal math skills is weakened; student internship there is also a big problem. 


\section{Reconstruction of structural system of mathematics education course}

The purpose of transformation and development of local undergraduate colleges is to improve the quality of personnel training and the ability of teachers to carry out applied research through the transformation and development. "Application-oriented undergraduate education belongs to vocational education" [1], mathematics and applied mathematics is a "theoretical and applied professional", available in the training of "four combined, four key" model, namely the curriculum system settings and job requirements The combination of basic theory teaching and basic skills training should focus on cultivating the students' basic skills. The combination of professional theoretical teaching and practical teaching should be given priority to practical teaching. The organic combination of education and vocational education should focus on training students The professional quality of ability [2], therefore, should adjust the curriculum system, the integration of course content.

According to the current situation of mathematics pedagogy curriculum content setting and the transformation and development of colleges and universities, it is necessary to completely change the existing curriculum content and system. The basic principles of reform are as follows: According to the connotation of mathematics teacher's specialization, the requirements of mathematics teacher's maths' qualities and the contradictions within the curriculum based on the maths education, the content of the whole course is determined according to the students'demand, the reasonable curriculum content structure, Not necessarily strictly in accordance with the discipline system to write, you can jump, you can select the important modules related to mathematics teaching and appropriate adjustments and integration, the development of comprehensive school-based curriculum.

Construct a mathematical education pedagogical system integrating theory and practice, divide the mathematics education class that has been subdivided in the past into several modules, such as deleting and integrating mathematics education modules, form an integrated mathematics pedagogy course and reduce the total teaching hours. It can be composed of three teaching modules: mathematics education theory, mathematics education technology and mathematics education practice curriculum [3]: the content of theoretical knowledge learning can be divided into professional culture and professional theory: the basis of professional culture can be composed of the following topics: modern mathematics Overview, high point of view under the elementary mathematics, mathematics competitions, mathematics history selection and mathematical methodology, mathematical culture; professional theory can be composed of the following topics: mathematics teaching theory, mathematics curriculum theory, mathematics learning theory, mathematics education evaluation, mathematics education research And thesis writing.

The practical skills courses mainly consist of the combination of educational skills modules and teaching practice modules, such as the teaching of simulated lectures in mathematics classroom, training of microteaching, document retrieval, production of CAI courseware, geometrical drawing board, education internship and internship, research training of mathematics education subject, Essay writing and a series of related issues [4].

Finally, these modules will be organically combined, and finally form a reasonable module group. And the content of each module should continuously reflect the new progress of mathematical education research, integrate into the new achievements related to it, pay attention to the research of "new teaching material" in teaching reform and update the outdated old contents.

\section{Mathematics Education Curriculum Implementation}

Normal students graduate after the employer generally reflect their level of knowledge and field of vision can be, but the basic teaching is not very good, and some normal students can not even design a course, let alone to cultivate the ability of middle school students. In view of this situation, in addition to carrying out the reform of the overall curriculum system, we must also focus on the implementation of the curriculum. 
Attention should be paid to the basic theory of mathematics education and teaching, such as the determination of teaching objectives, the principles, methods and models of mathematics teaching, the process of mathematics teaching and learning, and the teaching of mathematics teaching knowledge. However, in the specific teaching, instead of repeating the general theory in psychology, students should understand the similarities and differences between general theory and special theory and let students internalize theoretical knowledge in concrete mathematical classroom examples so as to reduce the overlap between the two Theoretical knowledge.

Integrate the modules of "Modern Mathematics Overview", "Elementary Mathematics from a High Perspective" and "Secondary Mathematics Textbook Analysis", introduce some important ideas of modern mathematics in a simple and easy way in the module of "Overview of Modern Mathematics" The new progress of modern mathematics has an overall view and insight on all branches of modern mathematics and opens up a new road for students to attain higher mathematics accomplishments. At the same time, using "high point of view" to treat "elementary mathematics" will make students realize that only by basing themselves on higher viewpoints can "condescend to list the mountains" so that students can truly grasp the mathematics system of middle school and realize their mathematical ideas so as to achieve their goal in teaching 庖解 solution of cattle, ease; for individual in the "competition math", number theory, combination of mathematics and other content overlap can be reduced.

Declarative knowledge and procedural knowledge are indispensable knowledge to become qualified teachers, which can be obtained through the study of mathematics education theory courses and practical skills courses. Therefore, we should integrate mathematics education theory course with skill course and practice course so as to realize the integration of three kinds of courses. For example, we can integrate mathematics teaching theory, micro-teaching and information technology together to form a complete system Mathematics education curriculum system.

Many students listed "math pedagogy" as "the most unpopular lesson" when they were in school. After a few years of working, they felt the importance of the lesson. Therefore, reforming the teaching methods and modes is a top priority.

In theory teaching, we should make full use of all kinds of resources, guide students to extensively access information, arrange research topics and carry out special discussions. For example, we carry out special discussions on the teaching methods of modern mathematics, the reform of mathematics teaching, the influence of teaching reform on mathematics and mathematical education. This will strengthen students' understanding of teaching theory and further develop their inquiry learning abilities. But also through the guidance of teachers, students self-study, group discussions, etc., to understand some of the hot spots in the reform of teaching materials abroad to jointly explore the new ideas of mathematical education reform.

In short, through the combination of theory and practice, the combination of extracurricular and extracurricular activities, and the combination of extracurricular and extracurricular teaching measures can both raise students 'theoretical level and enhance students' practical abilities.

\section{Mathematics Education Curriculum Evaluation}

In the assessment can make evaluation methods and methods of diversification, the establishment of a scientific and rational evaluation system. Such as the combination of theory and practice can be taken to test the combination of concentration and decentralized approach, focusing on the process of assessment, evaluation from the usual results, final grade, practice scores, and the usual operation to establish learning electronic portfolio, the implementation of portfolio evaluation, Performance evaluation, personality evaluation (competition results and awards) and other integrated quality evaluation. The usual results and the proportion of practice scores were increased to $30 \%, 40 \%$ of final exams, of course, you can also determine the proportion of the three according to the actual situation.

There are many teaching reforms involved in the transformation of colleges and universities, such as the construction of teaching staff, the development of training programs and syllabus, the 
preparation and rational use of teaching materials, the arrangement of teaching hours and so on. The construction of the curriculum system is also a complicated systematic project. It requires the joint efforts of a large number of teachers in higher normal colleges and universities to continuously explore, study, supplement and improve.

\section{Acknowledgements}

2016 Ningxia higher school science research project "Ningxia colleges and universities mathematical maths view of the status quo of mathematics research", project number NGY2016171;

The 2017 sub-project "Mathematics teacher education class teaching team construction", a sub-project of mathematics and applied mathematics of key project of undergraduate teaching quality and teaching reform project in colleges and universities;

Ningxia Teachers College "western first-class" discipline education science project "under the background of the reform of mathematics education curriculum modular system construction", project number YLXKYB1708

\section{References}

[1] Zhang Jian. Applied undergraduate equal to the undergraduate you [N]. China Education News, 2013-03-31.

[2] Yan Xinping school-enterprise cooperation pushed the "double subject" cooperative education [N]. China Education News, 2013-03-31.

[3] Sun Qingli, Wei Xifeng, Liu Xuejun. Mathematical teaching theory module design and practice [J]. Discipline education, 2009 (20).

[4] Luan Qingfang. Discussion on the Integration of Higher Vocational Mathematics Theory Education Curriculum and Practical Skills Curriculum [J]. Journal of Hefei Teachers College, 2010, 28 (6): 8. 